\title{
Standardisation of Enterprise Architecture Development for Smart Cities
}

\author{
Zohreh Pourzolfaghar and Viviana Bastidas \\ School of Computing \\ Dublin City University (DCU) \\ Dublin, Ireland \\ zohreh.pourzolfaghar@dcu.ie \\ viviana.bastidasmelo2@mail.dcu.ie
}

\author{
Aleksas Mamkaitis and Markus Helfert \\ School of Computing \\ Dublin City University (DCU) \\ Dublin, Ireland \\ aleksas.mamkaitis2@mail.dcu.ie \\ markus.helfert@dcu.ie
}

\begin{abstract}
Managing the complexity of the Information and Communications Technology (ICT) services in smart cities raises a need to use enterprise architecture frameworks to solve the complexity issues. However, the majority of the existing enterprise architecture frameworks have been developed to address the concerns and issues of the stakeholders in their associated world. To address challenges including complexity, multi-stakeholders and the serviceoriented nature of smart cities, this paper presents an enterprise architecture framework that can be used as a way to manage enterprise architectures in smart cities. This framework focuses on establishing contextual requirements and definitions for smart city systems and services. In contrast to other approaches, in this paper we focus on two important layers, i.e., context layer and service layer, as well as their relationships. The framework is valuable in developing smart services. It also contributes to the understanding of smart city enterprise architectures.
\end{abstract}

Keywords-smart cities; enterprise architecture; smart services.

\section{INTRODUCTION}

Smart cities are complex systems, which use ICT services to improve citizens' quality of life. One of the current issues in smart cities is dealing with complexity of ICT services. For instance, challenges to connect various systems in smart cities [10] are due to the complexity of the smart cities. During the last decades, many Enterprise Architecture (EA) frameworks have been developed to manage complex information systems, processes and infrastructures in organisations and systems. Each of these enterprise architecture frameworks has been developed to address specific needs and concerns of the stakeholders and issues for their world [1]. According to a study comparing the frameworks by [1], we draw the conclusion that some of the well-known enterprise architecture frameworks have not considered the aspects which are critical for smart cities. Referring to the definitions for smart cities, the realisation of smartness is happening by providing services to the citizens [36]-[40][59]. Therefore, citizens (users) view is crucial for delivering effective services. Another example is related to the service life cycle. According to the comparison results by [1], the maintenance phase has been neglected for the majority of the frameworks. From the smart city perspective, a maintenance phase is crucial to deliver qualified and sustainable services to the citizens. Indeed, maintainability and sustainability are two of the quality factors [2] for smart cities.

According to the above mentioned discussion, an enterprise architecture framework for smart cities should consider smart city stakeholders and their concerns for improving the quality of life for citizens. For this purpose, we introduce a methodological framework to manage smart city enterprise architecture which can be used as a standardised approach to develop smart services. This framework contains two new layers, including the context and service layers, as well as the initial relationships between them. This paper aims to introduce the components and concepts to establish the new layers and relationships.

The remainder of the paper is organised as follows. In Section 2, five well-known enterprise architecture frameworks are reviewed to define the problem. In Section 3, the presented enterprise architecture for smart cities is introduced. In Section 4, it is explained how the evaluation of the created architecture is performed through simulation. In the discussion section, we argue that the presented enterprise architecture for smart cities can deal with smart city stakeholders and their concerns, leading to enhancement of the quality of the delivered services to the citizens.

\section{RESEARCH METHOD}

This paper follows the design science research approach by [3] and [11] to present an enterprise architecture framework for smart cities. According to this research method, the first step is to define the problem. For this purpose, some well-known enterprise architecture frameworks are explored with regard to critical views for smart cities, i.e. citizens (user) view and their related phases in SDLC. The second step is to propose a solution for the recognised problem. To build up the solution artefact, this research follows the layered structure of an existing architecture by [7]. Then, relying on the related literature, the steps to construct the architectural layers and their relationships are elaborated. At last step, simulation is introduced as a method to assess the generated architecture. For this purpose, the created architecture for a service usecase in River city is evaluated and discussed. 


\section{LITERATURE REVIEW TO DEFINE THE PROBLEM}

\section{A. Existing Enterprise Architecture Frameworks}

Designing an enterprise is a system engineering approach to determine the required capabilities for designing the organisation, processes, services, information, and technologies [12]. Architectures are created usually to manage and organise the complexity of systems. Architectures are utilised to construct blueprints of an enterprise for organising system components, e.g., interfaces, processes, services and much more [4]. Booch [5] stated that enterprise architecture is the way to architect and plan the enterprise to have the best human performance and output.

To describe and model various aspects of enterprises, researchers have proposed different approaches [7]. Most frameworks follow a process and integration aim [13]. Enterprise architectures usually consist of two main approaches: an enterprise architecture Framework together with an implementation methodology [14]. A common approach among prominent frameworks is the transition and implementation from strategic business objectives into the infrastructure and systems design. Enterprise architecture aims to support and enable this transition by providing ways to design concepts of an enterprise.

Usually frameworks use views and layers to describe architectural elements to manage complexity (e.g., process, service, and technology). Each of the views illustrates a different perspective meaningful to specific stakeholders. Layering decomposes a system into groups of related components whose processes provide services to subsequent layers. For instance, components like sensors at technology layer support an application layer by providing data to them.

Over the last decades, number of enterprise architecture frameworks including the Zachman Framework [6], Department of Defense Architecture Framework (DoDAF) (Chief Information Officer U.S. Department of Defense 2010), Federal Enterprise Architecture Framework (FEAF) [8] (Office of Management and Budget 2012), Treasury Enterprise Architecture Framework (TEAF), and The Open Group Architectural Framework (TOGAF) [9], have been developed. Common to these frameworks is reducing enterprises' complexities by considering disparate viewpoints and organising various aspects in ways that make an enterprise understandable. Despite of existing overlaps and similarities between these frameworks, each of them was designed to address specific needs and concerns of the stakeholders and issues for their world [1].

To specify the targeted concern and stakeholders of each framework, this study adopts the results of a comparison study by [1], whether the enterprise architecture frameworks encompass the entire software development life cycle (SDLC), as well as all stakeholders' views. The character ' $\mathrm{Y}$ ' in the cells implies that the corresponding framework has provided details for the SDLC phase, or considered mentioned stakeholders' views. The adopted results are shown in Table I.
TABLE I. COMPARISON OF THE ENTERPRISE ARCHITECTURE FRAMEWORKS (ADOPTED FROM [1])

\begin{tabular}{|c|c|c|c|c|c|c|c|c|c|c|c|}
\hline \multirow[b]{2}{*}{ Framework } & \multicolumn{5}{|c|}{ SDLC Phases } & \multicolumn{6}{|c|}{$\begin{array}{c}\text { Views/Perspe } \\
\text { ctives }\end{array}$} \\
\hline & 㫋 & 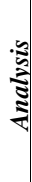 & 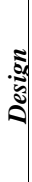 & $\begin{array}{c}\mathbf{5} \\
\mathbf{5} \\
\mathbf{5} \\
\mathbf{5} \\
\mathbf{5} \\
\mathbf{5} \\
\mathbf{5} \\
\mathbf{5}\end{array}$ & 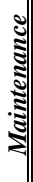 & 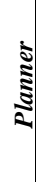 & 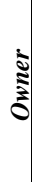 & : & 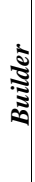 & 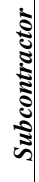 & ș \\
\hline Zachman & $\mathrm{Y}$ & $\mathrm{Y}$ & $\mathrm{Y}$ & $\mathrm{Y}$ & - & $\mathrm{Y}$ & $\mathrm{Y}$ & $\mathrm{Y}$ & $\mathrm{Y}$ & $\mathrm{Y}$ & $\mathrm{Y}$ \\
\hline DoDAF & $\mathrm{Y}$ & $\mathrm{Y}$ & $\mathrm{Y}$ & $\mathrm{Y}$ & - & $\mathrm{Y}$ & $\mathrm{Y}$ & $\mathrm{Y}$ & $\mathrm{Y}$ & - & - \\
\hline FEAF & $\mathrm{Y}$ & $\mathrm{Y}$ & $\mathrm{Y}$ & $\mathrm{Y}$ & - & $\mathrm{Y}$ & $\mathrm{Y}$ & $\mathrm{Y}$ & $\mathrm{Y}$ & $\mathrm{Y}$ & - \\
\hline TEAF & $\mathrm{Y}$ & $\mathrm{Y}$ & $\mathrm{Y}$ & $\mathrm{Y}$ & - & $\mathrm{Y}$ & $\mathrm{Y}$ & $\mathrm{Y}$ & $\mathrm{Y}$ & & - \\
\hline TOGAF & - & $\mathrm{Y}$ & $\mathrm{Y}$ & $\mathrm{Y}$ & - & - & $\mathrm{Y}$ & $\mathrm{Y}$ & & - & - \\
\hline
\end{tabular}

Reviewing Table I, empty (gray) cells unfold that critical aspects from smart city perspective have not been considered in the explored enterprise architecture frameworks. The first observation is that the user view has received the least attention, while the citizens/users are paramount in smart cities. According to the definition for smart services by [42], the ultimate goal for services in smart cities is to respond to the citizens' needs and concerns. Consequently, citizens (users) concerns are crucial in the enterprise architecture for smart cities.

The second observation is related to the maintenance phase which is of concern for authorities in smart cities, due to sustainability of the delivered services. As [2] stated sustainability and all other quality factors are crucial to realise smartness in the cities. Many standards (e.g., sensor security standards, [2]), and principles (e.g., open data), have been developed in smart cities, as the enablers of quality factors (e.g., security, confidentiality, [2]). In summary, it is concluded that some important aspects from smart city perspective cannot be addressed by the explored enterprise architecture frameworks. To address these challenges, this paper introduces an enterprise architecture in the following section.

\section{DESIGNING ENTERPRISE ARCHITECTURES FOR SMART CITIES}

The overall view of the enterprise architecture for smart cities includes strategic and operational components as follows: vision and strategy management, portfolio management, service design, implementation and change management (See Figure 1). 


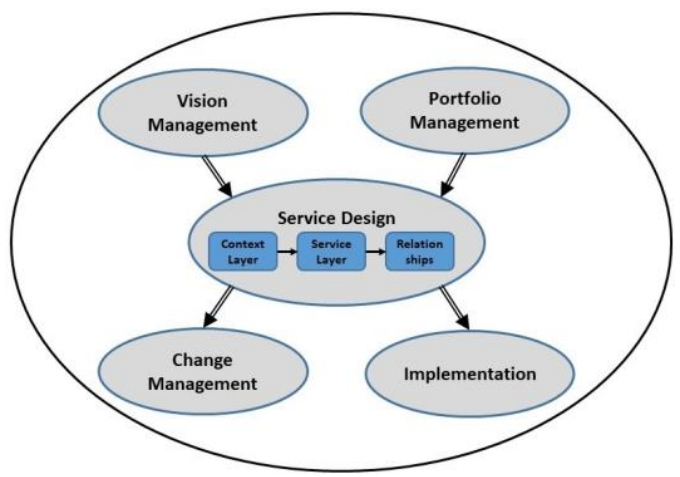

Figure 1. General overview of the framework to develop the presented enterprise architecture for smart cities

The focus of this paper is on the service design part. With this aim, this study follows [7] to put the architectural layers together. The presented layered architecture includes: Context layer, service layer, information system layer and technology layer (Figure 2).

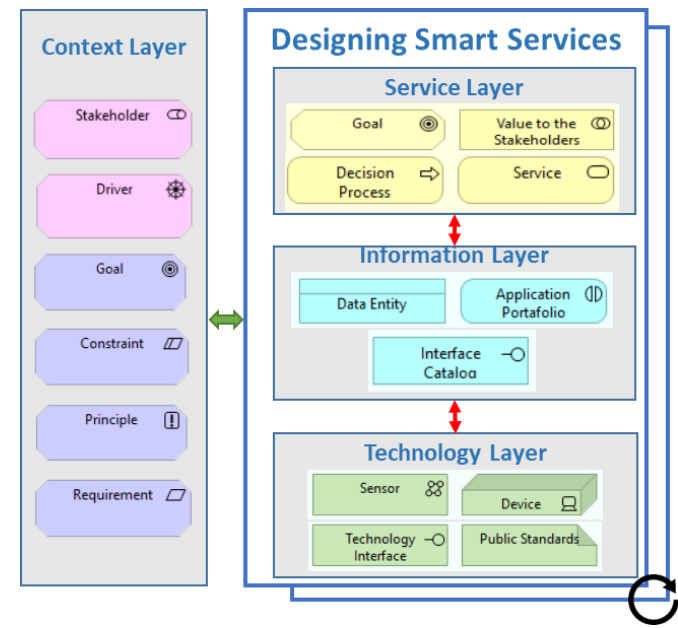

Figure 2. Overview of the architectural layers for design of services

The first two layers, i.e., context layer and service layer, have been initiated by this research for the first time. The context layer plays an important role to capture the contextual concerns from 'vision management' and transfer them to the service layer. In service layer, these requirements are considered to provide a detailed service description which will have relationships with information system layer and technology layer. A summary of the aims of focus of the presented layers is shown in Table II.

TABLE II. COMPARISON OF THE ENTERPRISE ARCHITECTURE FRAMEWORKS (ADOPTED FROM [1])

\begin{tabular}{|c|l|}
\hline $\begin{array}{c}\text { Architectural } \\
\text { Layer }\end{array}$ & \multicolumn{1}{|c|}{ Aim and Focus } \\
\hline Context & $\begin{array}{l}\text { To capture smart city context information } \\
\text { about strategies, priorities and other critical } \\
\text { aspects (e.g., stakeholders and their concerns), } \\
\text { required to deliver effective services to the } \\
\text { citizens. }\end{array}$ \\
\hline Service & $\begin{array}{l}\text { To define appropriate goals, scope and etc. for } \\
\text { services with regard to the smart city }\end{array}$ \\
\hline
\end{tabular}

\begin{tabular}{|l|l|}
\hline & requirements, concerns and priorities. \\
\hline Information & $\begin{array}{l}\text { To identify the data elements, data flows and } \\
\text { the data interrelations required to support } \\
\text { service function [4]. }\end{array}$ \\
\hline Technology & $\begin{array}{l}\text { To support information function and the } \\
\text { system/application function [4]. }\end{array}$ \\
\hline
\end{tabular}

In the following three sub-section more details are provided for three main processes to capture smart city context information, to develop service description, and to relate the service description to the information layer.

\section{A. Context Layer}

To define the context layer, this study relies on two definitions for smart cities and smart services, and a taxonomy of the smart city requirements by [42]. The selected definitions are as below:

Smart cities are innovative cities which use ICT to facilitate daily activities of citizens to improve their quality of life [58].

Smart services are the services which respond to the smart city stakeholders concerns and fulfil smart city quality factors [42].

Regarding the above mentioned definitions, the context layer constitutes of the components to specify the stakeholders, their concerns, quality factors and their enablers/drivers. According to the taxonomy, the main stakeholders in smart cities are classified as follows: citizens, authorities, and service developers. Each of these stakeholders have their own specific concerns. Some examples of these concerns are: lower cost (for citizens), realisation smartness (for authorities), and more benefits and market share (for service developers). Likewise, the quality factors are defined as another component of the context layer. The quality factors (e.g., maintainability, interoperability, usability) should be fulfilled by the services in smart cities. The next two components are related to the enablers of the quality factors, i.e., standards (e.g., sensor security standards), and principles, (e.g., data principles). For any specific service, related standards and principles are required to be considered. Another component for context layer is the constraints (e.g., contractual constraints). This component is to avoid some consequences like low quality services, which are arising from some constraints like time and cost limitations. The last component for this layer is about documenting all the above mentioned initial considerations. The outcome of this process is a comprehensive collection of the considerations which have been defined based on the requirements and concerns for smart cities. All the above mentioned details are summarised in the form of a process. The defined activities for this process are as below:

- Specify smart city stakeholders, (considering the defined classes of stakeholders) to specify the target stakeholders for a specific service/initiative

- Specify stakeholders' concerns for various classes of stakeholders, to specify the target concern to be addressed by the service/initiative 
- Specify the quality factors to be met by the service/initiative

- Specify related standards in the target domain for the service/initiative

- Specify related principles to enable the quality factors

- Specify the constraints (e.g., the budget for the project), to define appropriate goals for service/initiative

- Documenting all the considerations and specifications by the previous activities

All the before mentioned activities for this layer are utilised to define appropriate goal and scope for smart services/initiatives. In this way, alignment of the designed services with ultimate goal of the smart cities (which is improvement of quality of life) is ensured.

\section{B. Service Layer}

Service layer describes the "operant" resources of the service system, specifically service actors and their interactions. The types of service actors can be private persons, organizations, governments, and even countries, depend on the context [15] and the depth of service and service system analysis. This layer does not include resources, such as information or technology, and their function is to support actors and their interactions in the Service Layer.

Further, we present activities for the service system description. The aim of these activities is to extract and record contextual information for service modelling and design.

- Commence a service description including the necessary stakeholders who can provide the relevant service design information [16]

- Identify a function of the service [17] and [18] and its positioning within the Smart City domains [19][21]

- Articulate a use-case for the service [22]

- Clarify an exchange medium for service remuneration [23]-[27]

- List service actors [28] and types of their interactions

- Identify actor resources [29] based on each service actor contributions to the service

- Define an experience and Value proposition [27][30][31] that service is intending to provide

- Perform a PESTLE analysis to further understanding of the context within which the service will operate [32]-[34]

- Complete a service description by consolidating the information gathered from the domain [35].

The purpose of a service description is to provide a sufficient amount of information towards the Service System modelling and design.

\section{Relationships}

The service layer defines components such as city services, domains, stakeholders, locations, etc. to support the smart city goals and to facilitate and optimize intelligent decision making [42]-[44]. The information layer defines components such as applications, software services and data to support the automation or realization of city services [41][45][46]. The service layer and the information layer are physically and logically disconnected at the moment. Smart city architectures do not support the relationships across these architectural views. The identification of the architectural concepts and their relationships are essential for providing an alignment between these layers.

Smart city architectures must support the connection between service and information layers to ensure that citizens' needs are met by solutions provided by information technology [47]. However, in practice, smart city architectures do not present an application process to establish the relationships between the service and information layers. This makes smart city architectures fail to provide a foundation to guide the modelling of integrated and coherent models which meet the citizens' needs. The resulting models can fail to support the analysis, implementation, and maintenance of such city services.

To tackle this problem, this section defines a process for an alignment of service and information layers in smart city architectures. The proposed process aims to define the key activities regarding an identification of the relationships between architectural concepts of the service layer and the information layer. The key activities of a proposed process are defined as follows.

- Specify different smart city domains (e.g., health, education, mobility, environment, tourism, etc.) for each city service [48] and [49]

- Define the required data entities for each stakeholder (e.g., city authorities, citizens, communities, retailers, etc.) [50] and [51]

- Define the data entities which are provided or consumed by each city service [50] and [51]

- Define the digital tools, monitoring applications, application modules, or another deployable component to support each city service [44] and [52]

- Capture the location or place (e.g., roads, bridges, airports, tunnels, buildings, etc.) where software services operate [53] and [54]

- Define the required software services which support each city service [55] and [56]

- Specify a domain (e.g., health, education, mobility, environment, tourism, etc.) to which the software services belong [44][46][57]

The above mentioned process has been established to ensure appropriate relationships between the service and information layers. Also, it aims to help researchers and practitioners as follows. First, it helps organizations that need to design an architecture for smart cities to understand the issues associated with the relationships between these layers. Second, a formalisation of this process can help them to 
realise important advances in the design of more effective smart city architectures and make an industrial uptake of architectures research efforts easier. Finally, the proposed process supports the connection between the service and information layers to ensure that citizens' needs are met by city solutions provided by information technology.

\section{EVALUATION}

In this section, we will explain how the quality of a specific architecture can be evaluated by simulation. SimEvents software provides a simulation framework for analysing event-driven models to optimise performance characteristics such as latency, workload, conversion, and entity loss. Generators, switches, queues, servers and other predefined blocks enable us to model various important aspects of the system architecture such as processing delays, routing, prioritisation for communication and scheduling tasks.

A discrete-event system in a Simulink model is usually constructed from various blocks such as, generators, queues and servers. These blocks are used for producing and processing our entities, which represent discrete items of interest. Examples of entities are network packets in a communication system, customers in a restaurant, sensor readings or footfalls in an enterprise application. The motion and changes in entity attributes, corresponding to asynchronous events, update the system states such as length of a queue or entity service time in a server. In discrete-event systems, asynchronous discrete incidents (events) cause and affect the state transitions of the system.

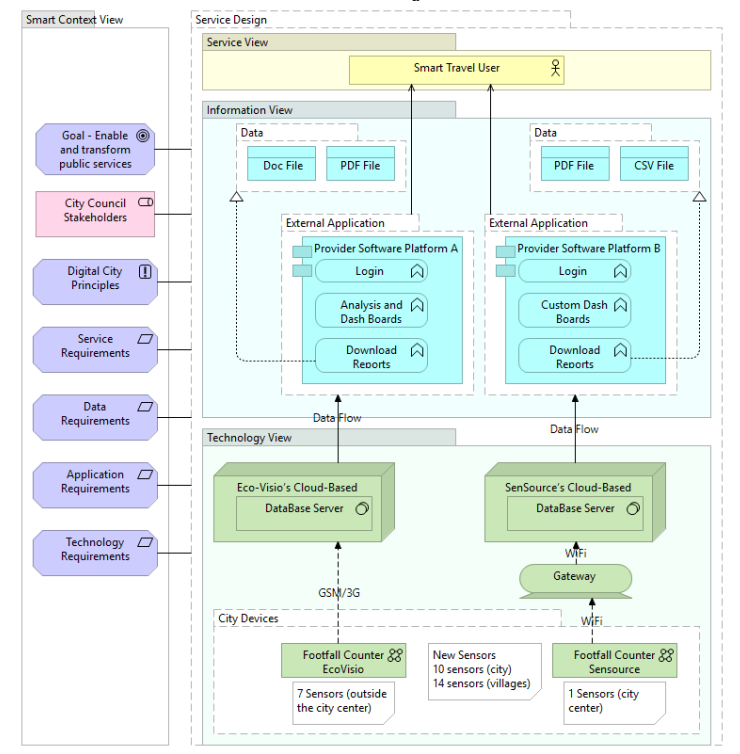

Figure 3. The real use-case from River city.

Figure 3 shows a very simple real use-case in the River city. The created architecture for the use-case stands on the presented enterprise architecture for smart cities. For this study's purpose, the right-side of the architecture shown in the figure is modelled. Specifically, we are interested in the effect of the Number of Processed Entities on the overall latency of the system which is measured by the number of entities reached the final destination.

For demonstration purposes, we will show two different results based on two different values of the "number of servers" property. For this purpose, the simulation is run for 100 time units, and is represented as the $\mathrm{x}$ axe in the following Figures 4, 5.

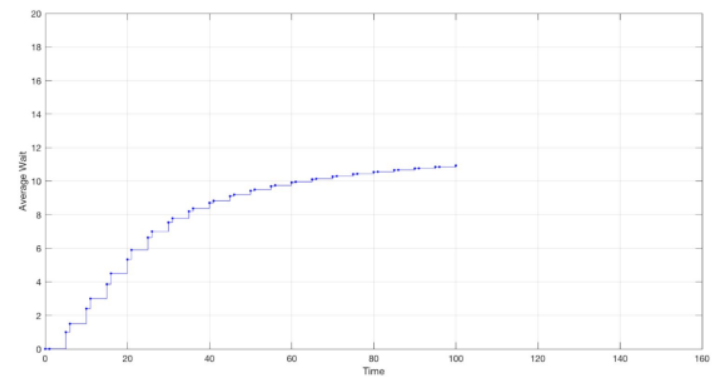

Average time of entities waiting in the queue to be processed

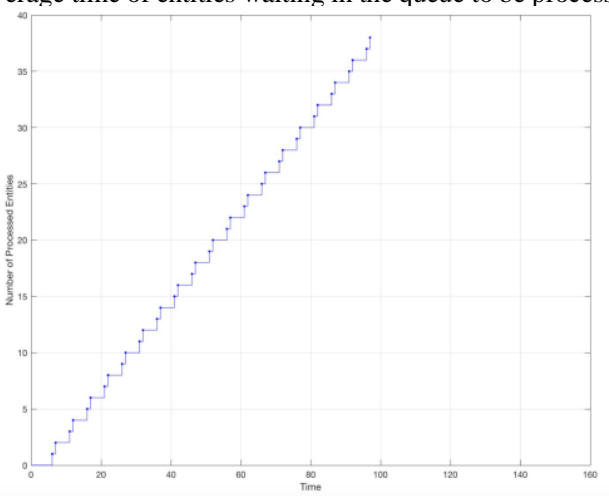

Number of processed entities reached the final destination

Figure 4. First Run (number of servers $=2$ ).

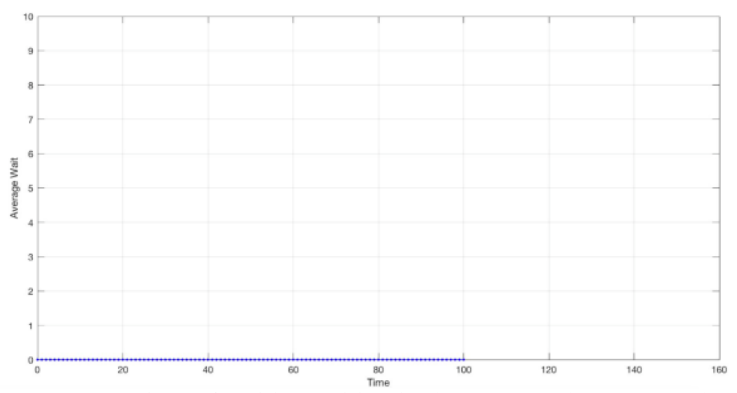

Average time of entities waiting in the queue to be processed

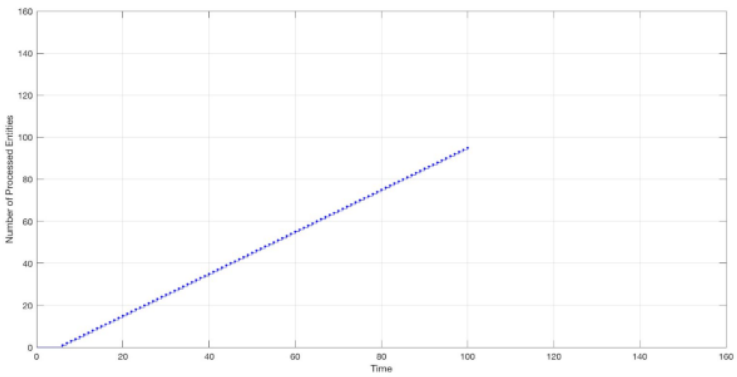

Number of processed entities reached the final destination

Figure 5. Second Run (number of servers $=5$ ). 
It is obvious that an increase of the processing power (by increasing the number of servers from 2 to 5) leads to decrease of waiting time to almost zero. In addition, the final number of entities reached the final destination have become linear with the time. This simulation demonstrates how to evaluate the architectures which are created based on the presented smart city enterprise architecture.

\section{DISCUSSION AND CONCLUSION}

Smart cities are complex systems which provide enormous ICT services to the citizens to improve their quality of life. Complexities in smart cities cause difficulties in management of provided services in terms of achieving smart city goals. Many years ago, enterprise architecture have been posed to solve complexity issues for organisations and systems. However, smart cities and organisations have different nature. Smart cities are service-oriented and organisations are business-oriented. Addressing the challenges arising from this difference, this paper presented the steps for designing new layers and relationships necessary for development of architectures for smart cities service. The first layer, i.e., context layer aims to capture smart city contextual information and transfer it to the service layer. The service layer provides information on service descriptions. This information is utilised by both, information and technology, layers. The relationships enable communications between the service layer and the information layer. The future study for this research will be defining other required relationships, e.g., between the service layer and the technology layer. The outcome of this research contributes to development of a reference architecture for smart cities.

\section{ACKNOWLEDGMENT}

This work was supported by the Science Foundation Ireland grant " $13 / \mathrm{RC} / 2094$ " and co-funded under the European Regional Development Fund through the Southern and Eastern Regional Operational Programme to Lero - the Irish Software Research Centre (www.lero.ie).

\section{REFERENCES}

[1] L. Urbaczewski and S. Mrdalj, "A comparison of enterprise architecture frameworks," Issues in Information Systems, vol. 7, no. 2, 2006, pp.18-23.

[2] G. Kakarontzas, L. Anthopoulos, D. Chatzakou and A. Vakali, "A conceptual enterprise architecture framework for smart cities: A survey based approach," in e-Business (ICEB), 11th International Conference on IEEE, 2014, pp. 47-54.

[3] K. Peffers, T. Tuunanen, M. A. Rothenberger and S. Chatterjee, "A design science research methodology for information systems research," Journal of management information systems, vol. 24, no. 3, 2007, pp. 45-77.

[4] D. Minoli, Enterprise architecture A to Z: frameworks, business process modeling, SOA, and infrastructure technology, CRC press, 2008.

[5] G. Booch, "Enterprise architecture and technical architecture," IEEE Software, vol. 27, no. 2, , 2010, pp. 96.

[6] J. A. Zachman, "A framework for information systems architecture," IBM systems journal, vol. 26, no. 3, 1987, pp. 276-292.
[7] M. Meyer, M. Helfert and C. O'Brien, An analysis of enterprise architecture maturity frameworks. In Perspectives in Business Informatics Research. Berlin, Heidelberg: Springer, 2011, pp. 167-177.

[8] FEAF, The Chief Information Officers Council, Federal Enterprise Architecture Framework (FEAF) v1.1, 1999.

[9] The Open Group, The Open Group Architecture Framework TOGAF Version 9.1, 2011.

[10] Z. Pourzolfaghar and M. Helfert, Integration of Buildings Information with Live Data from IoT Devices, in Connected Environments for the Internet of Things. Cham: Springer, 2017, pp. 169-185.

[11] L. Ostrowski and M. Helfert, "Design science evaluationexample of experimental design," Journal of Emerging Trends in Computing and Information Sciences, vol. 3, no. 9, 2012, pp. 253-262.

[12] R. E. Giachetti, Design of enterprise systems: Theory. architecture, and methods. Florida, 2010.

[13] J. W. Ross and G. Westerman, "Preparing for utility computing: The role of IT architecture and relationship management," IBM Systems Journal, vol. 43, no. 1, 2004, pp. 5-19.

[14] B. D. Rouhani, M. N. R. Mahrin, F. Nikpay, R. B. Ahmad and P. Nikfard, "A systematic literature review on enterprise architecture implementation Methodologies," Information and Software Technology, vol. 62, 2015, pp. 1-20.

[15] J. Spohrer, L. Anderson, N. Pass and T. Ager, "Service science and service-dominant logic," In Otago Forum, vol. 2, no. 2, 2008, pp. 4-18.

[16] J. Cardoso, A. Barros, N. May and U. Kylau, "Towards a unified service description language for the internet of services: Requirements and first developments," In Services Computing (SCC), IEEE International Conference, 2010, pp. 602-609.

[17] C. H. Lovelock, Developing and managing the customerservice function in the service sector. The Service Encounter: Managing Employee Customer Interaction in Service Business, Lexington, MA: Lexington Books, 1985, pp. 26580.

[18] Q. Su, Z. Li, Y. T. Song and T. Chen, "Conceptualizing consumers' perceptions of e-commerce quality," International Journal of Retail and Distribution Management, vol. 36, no. 5, 2008, pp. 360-374.

[19] T. Nam and T. A. Pardo, "Conceptualizing smart city with dimensions of technology, people, and institutions," in Proceedings of the 12 th annual international digital government research conference: digital government innovation in challenging times,ACM, 2011, pp. 282-291.

[20] P. Neirotti, A. De Marco, A. C. Cagliano, G. Mangano and F. Scorrano, "Current trends in Smart City initiatives: Some stylised facts," Cities, vol. 38, 2014, pp. 25-36.

[21] R. Giffinger and N. Pichler-Milanović, Smart cities: Ranking of European medium-sized cities. Vienna: Centre of Regional Science, 2007.

[22] S. Adolph, A. Cockburn and P. Bramble, Patterns for effective use cases. Addison-Wesley Longman Publishing Co., Inc., 2002.

[23] R. G. Hansen, "A theory for the choice of exchange medium in mergers and acquisitions," Journal of business, 1987, pp.75-95.

[24] R. G. Hansen, "A theory for the choice of exchange medium in the market for corporate control," Journal of Business, vol. 60, no. 1, 1987, pp.75-95.

[25] S. Bignoux, "Short-term strategic alliances: a social exchange perspective," Management decision, vol. 44, no. 5, 2006, pp. 615-627. 
[26] M. Nowak and K. Sigmund, "A strategy of win-stay, loseshift that outperforms tit-for-tat in the Prisoner's Dilemma game," Nature, vol. 364, no. 6432, 1993, p. 56.

[27] B. Edvardsson, B. Tronvoll and T. Gruber, "Expanding understanding of service exchange and value co-creation: a social construction approach," Journal of the Academy of Marketing Science, vol. 39, no. 2, 2011, pp. 327-339.

[28] J. M. Bryson, "What to do when stakeholders matter: stakeholder identification and analysis techniques," Public management review, vol. 6, no. 1, 2004, pp. 21-53.

[29] S. Albert, B. E. Ashforth and J. E. Dutton, "Organizational identity and identification: Charting new waters and building new bridges," Academy of management review, vol. 25, no. 1, 2000, pp. 13-17.

[30] P. Frow and A. Payne, "A stakeholder perspective of the value proposition concept," European journal of marketing, vol. 45 , no. $1 / 2,2011$, pp. $223-240$.

[31] C. Gentile, N. Spiller and G. Noci, "How to sustain the customer experience:: An overview of experience components that co-create value with the customer," European management journal, vol. 25, no. 5, 2007, pp. 395-410.

[32] G. C. Peng and M. Nunes, "Using PEST analysis as a tool for refining and focusing contexts for information systems research."

[33] F. M. E. Team, PESTLE Analysis. Strategy Skills. Free management ebooks, 2013, p. 15.

[34] P. Newton, What is the PESTLE Analysis? 2014.

[35] A. Arsanjani, "Service-oriented modeling and architecture," IBM developer works, vol. 1, 2004, p. 15.

[36] R. E. Hall, "The vision of a smart city," in Proceedings of the 2nd International Life Extension Technology Workshop, Paris, France, 2000.

[37] L. Anavitarte and B. Tratz-Ryan, "Market Insight: Smart Cities" in Emerging Markets, Gartner, Stamford, CT, 2010, pp. 39-61.

[38] D. Ludlow and Z. Khan, "Participatory democracy and the governance of smart cities," in Proceedings of 26th Annual AESOP Congress, Ankara, Turkey, 2012.

[39] J. Fenn and M. Raskino, Gartner's hype cycle special report for 2011, Stamford, CT: Gartner, 2011.

[40] R. Giffinger, C. Fertner, H. Kramar, R. Kalasek, N. PichlerMilanovic and E. Meijers, "Smart cities-Ranking of European medium-sized cities," Vienna: Centre of Regional Science, 2007.

[41] J. Massana, C. Pous, L. Burgas, J. Melendez and J. Colomer, "Identifying services for short-term load forecasting using data driven models in a Smart City platform," Sustain. Cities Soc., vol. 28, 2017, pp. 108-117.

[42] Z. Pourzolfaghar and M. Helfert, "Taxonomy of Smart Elements for Designing Effective Services," in Proceeding of 23rd American Conference of Information Systems (AMCIS), 2017, pp. 1-10.

[43] N. Mohamed, J. Al-Jaroodi, I. Jawhar, S. Lazarova-Molnar and S. Mahmoud, "SmartCityWare: A service-oriented middleware for cloud and fog enabled smart city services," IEEE Access, vol. 5, 2017, pp. 17576-17588.

[44] A. Hefnawy, A. Bouras and C. Cherifi, "IoT for Smart City Services," in Proceedings of the International Conference on Internet of things and Cloud Computing, 2016, p. 55.

[45] P. M. Singh, M. Van Sinderen and R. Wieringa, "Reference Architecture for Integration Platforms," IEEE 21 st Int. Enterp. Distrib. Object Comput. Conf., 2017, pp. 113-122.

[46] W. Rong, Z. Xiong, D. Cooper, C. Li and H. Sheng, "Smart city architecture: A technology guide for implementation and design challenges," China Commun., vol. 11, no. 3, 2014, pp. 56-69.
[47] L. Anthopoulos, "Defining Smart City Architecture for Sustainability," in Proceedings of 14th Electronic Government and 7th Electronic Participation Conference (IFIP2015), 2015, pp. 140-147.

[48] A. Gaur, B. Scotney, G. Parr and S. McClean, "Smart city architecture and its applications based on IoT," Procedia Comput. Sci., vol. 52, no. 1, 2015, pp. 1089-1094.

[49] P. Neirotti, A. De Marco, A. C. Cagliano, G. Mangano and F. Scorrano, "Current trends in Smart City initiatives: Some stylised facts," Cities, vol. 38, 2014, pp. 25-36.

[50] S. Consoli,V. Presutti, D. R. Recupero, A. G. Nuzzolese, S. Peroni and A. Gangemi, "Producing Linked Data for Smart Cities: The Case of Catania," Big Data Res., vol. 7, 2017, pp. $1-15$.

[51] A. Ilhan, R. Möhlmann and W. G. Stock, "A Community Architecture Framework for Smart Cities," Citizen's Right to Digit. City. Springer Singapore, 2015, pp. 231-252.

[52] M. Nitti, V. Pilloni, D. Giusto and V. Popescu, "IoT Architecture for a Sustainable Tourism Application in a Smart City Environment," Mob. Inf. Syst. 2017.

[53] P. Nesi, C. Badii, P. Bellini, D. Cenni, G. Martelli and M. Paolucci, "Km4City Smart City API: An Integrated Support for Mobility Services," in 2016 IEEE International Conference on Smart Computing, SMARTCOMP 2016, 2016.

[54] J. R. Gil-Garcia, T. A. Pardo and T. Nam, "What makes a city smart? Identifying core components and proposing an integrative and comprehensive conceptualization," Inf. Polity, vol. 20, no. 1, 2015, pp. 61-87.

[55] E. F. Z. Santana, A. P. Chaves, M. A. Gerosa, F. Kon and D. Milojicic, "Software platforms for smart cities: Concepts, requirements, challenges, and a unified reference architecture," arXiv Prepr. arXiv1609.08089, 2016.

[56] S. Clement, D. Mckee and J. Xu, "Service-Oriented Reference Architecture for Smart Cities," in Service-Oriented System Engineering (SOSE), IEEE Symposium, 2017, pp. $81-85$.

[57] N. Zakaria Bawany and J. A. Shamsi, "Smart City Architecture: Vision and Challenges," Int. J. Adv. Comput. Sci. Appl., vol. 6, no. 11, 2015, pp. 246-255.

[58] ITU-T FG-SSC, "Smart sustainable cities: An analysis of definitions," Technical report, ITU-T, 2014.

[59] M. L. Marsal-Llacuna and M. B. López-Ibáñez, "Smart urban planning: Designing urban land use from urban time use," Journal of urban technology, vol. 21, no. 1, 2014, pp. 39-56. 